\title{
Retórica y Estado de Derecho *
}

\author{
NEIL MACCORMICK \\ Universidad de Edimburgo
}

El lugar común de que las proposiciones jurídicas son intrínsecamente argumentables se opone al lugar común rival de que el Estado de Derecho (Rule of Law) es valorado en consideración a la certeza jurídica. La reconciliación de esos aparentes contrarios toma en cuenta las aportaciones de las teorías de la retórica y de las teorías procedimentales de la razón práctica, situando así el problema de la indeterminación del Derecho en el contexto del carácter cuestionable de la acción estatal en los Estados libres. Esto no es incompatible con, sino exigido por, el Estado de Derecho, que es indebidamente considerado como asegurador de la certeza jurídica; la certeza derrotable es lo que resulta más deseable o alcanzable.

\section{INTRODUCCIÓN}

El interés por el Estado de Derecho (Rule of Law) es señal de una sociedad civilizada. La independencia y dignidad de cada ciudadano se basa en la existencia de un "gobierno de leyes, no de hombres». Valores como la certeza y la seguridad jurídica son centrales en el contexto de la apología del Estado de Derecho. La idea de que el Derecho exhibe una moralidad interna en la consecución, siempre imperfecta aunque no siempre con igual imperfección, de estos valores es vigorosamente discutida. $\mathrm{E}$ incluso el Derecho que rige una sociedad civilizada parece ser un ámbito de interminables discusiones y disputas. Casi todo lo que se hace con el Derecho puede aparentemente ser problematizado en uno $u$ otro contexto, y pueden alegarse argumentos para rebatir las más preciadas certezas. Tan antigua como la exigencia del Estado de Derecho es el reconocimiento del ámbito del Derecho como un foro de argumentación, un ámbito propicio para la retórica en todo su discutible arte. Y la retórica puede aquí replegarse sobre sí misma. Argumentar a partir de los lugares comunes o tópicos es algo usual en la retórica, pero a veces las verdades de los lugares comuncs del pensamiento cotidiano pueden, como mínimo, aparentar estar en franca contradicción mutua. La idea del carácter argumentable del Derecho parece echar un jarro de agua fría a la idea de certeza o seguridad jurídica. ¿O no es así? ¿Existe alguna expectativa de reconciliación entre ambas? Lo que a continuación se presentará son algunas reflexiones

* Este trabajo es una versión modificada del presentado al Perelman Symposium en el $200^{\circ}$ World Congress in Philosophy celebrado en Boston en agosto de 1998. La traducción del original inglés ha sido realizada por Isabel Lifante. 
sobre la retórica y la argumentación en el Derecho encaminadas a tal reconciliación.

\section{PRIMER LUGAR COMÚN: EL CARÁCTER ARGUMENTABLE DEL DERECHO}

El Derecho es una disciplina argumentativa. Cualquier cuestión o problema sobre el que se picnse, si es planteado como una cuestión o problema jurídico, exige una solución o respuesta en términos de una proposición que parezca correcta $o$ al menos defendible, aunque preferiblemente concluyente, como cuestión de Derecho. Para comprobar si es correcto o genuinamente defendible o quizás incluso concluyente pensamos en los argumentos que podrían alegarse en favor de la respuesta o solución propuesta. Podemos examinar tales argumentos construyendo todos los contraargumentos que se nos ocurran. Si esto vale para una de las partes de la discusión, debe valer también para la otra. Al reflexionar sobre lo que parece ser el argumento o argumentos más fuertes de una de las partes se comprueba la fortaleza de los argumentos de la otra. $\mathrm{Al}$ resolver el caso contrario hay que enfrentarse con y, si es posible, derrotar a los abogados que logren presentar sus argumentos en su mejor forma posible.

Esto no es una ciencia exacta; ni siquiera es una ciencia, sino una habilidad práctica, un arte práctico. Aun así depende en gran medida del conocimiento y aprendizaje (cl Derecho no es inadecuadamente llamado una «profesión liberal») *. Los argumentos jurídicos son siempre, de algún modo, argumentos sobre el Derecho o argumentos sobre las cuestiones de hecho, de prueba, o de opinión; es decir, o bien éstos tienen que ver con el Derecho, o bien el Derecho tiene que ver con ellos. Tener y estar de hecho íntimamente familiarizado con un gran conjunto de conocimientos jurídicos es esencial tanto para el que crea como para el que evalúa argumentos de gran calidad en el Derecho. Por ello la ciencia jurídica, el estudio estructurado y ordenado de la doctrina jurídica, es un sostén esencial del Derecho como praxis. Muchas personas de vasta erudición muestran poca aptitud para la argumentación forense; a algunas de considerable aptitud y pericia les falta una completa formación para dominar el Derecho. Lo que se necesita es la combinación de ambas cosas.

El proceso de evaluación de la fuerza relativa de los argumentos en conflicto tiene que ser forzosamente una cuestión de grado, una cuestión de opinión, que requiere ser juzgada. Si los argumentos a menudo parecen estar prácticamente empatados, icómo puede decirse de alguno que sea el más fuerte? Probablemente la respuesta es que no puede decirse con certeza, no del modo

" La expresión inglesa para indicar «profesión liberal» es precisamente «leamed profession» [N. de la T.]. 
en que podría decirse con argumentos demostrativos ${ }^{1}$, dónde la aceptación de las premisas como axiomáticas o como verdades contingentes permite derivar de ellas una conclusión de la que no puede dudarse en la medida establecida por sus premisas. En el Derecho la convicción subjetiva es a veces posible cuando para alguien un cierto entramado de argumentos apunta firmemente hacia cierta conclusión, y todos los contraargumentos expuestos o en los que podría pensarse parecen fatalmente débiles en comparación. $\mathrm{Y}$ esto puede ser una certeza compartida o intersubjetiva en el caso de que una comunidad de expertos ${ }^{2}$ comparta tal opinión sobre la cuestión, incluso hasta el punto de tratarla prácticamente como un axioma. Pero tal convicción compartida, tal actitud compartida de estar en lo cierto sobre algo no es lo que se quiere decir cuando se habla de certeza en el otro sentido: que se trata de lo que es ciertamente verdad, crea alguien en ella o no.

Supongo que todo esto será un lugar relativamente común entre quienes tienen algún interés en el Derecho, bien como materia de estudio, bien como profesión práctica. Es la clave de la opinión común que conduce a posiciones conexas tales como: que el Derecho no es lógico; que la lógica no contribuye en nada al razonamiento jurídico; que el Derecho no tiene nada que ver con la verdad, sino sólo con lo que puede ser probado de acuerdo con los procesos jurídicos y los estándares probatorios aplicados a cualquier prueba que el Derecho considere relevante y admisible. El que tales posiciones derivadas sean realmente corolarios necesarios de nuestro lugar común de partida no es, ni mucho menos, obvio y será discutido en este trabajo. Pero el punto de partida se presentará a sí mismo como elemento clave de lo que debe ser asumido por quien quiera entender la naturaleza y el carácter del Derecho como una actividad práctica.

\section{SEGUNDO LUGAR COMÚN: EL ESTADO DE DERECHO}

Consideramos esto entonces como una tesis abierta sobre el Derecho: mientras que el Derecho sea lo que subyace a las demandas o acusaciones y defensas juridicas será algo argumentable a veces, aunque no siempre concluyentemente; como minimo, persuasivamente. A esto debe entonces oponérsele inmediatamente una antítesis, que también pertenece simplemente al lugar común: si el Derecho es fielmente observado, prevalece el Estado de Derecho, y las sociedades que viven bajo el Estado de Derecho disfrutan de grandes beneficios en comparación con aquellas que no. El Estado de Derecho es una situación

' Ronald Dworkin ha defendido con especial énfasis la tesis de que el carácter no demostrativo de los argumentos jurídicos no es, sin embargo, obstáculo para que sean argumentos correctos. Véase Law's Empire (London: Fontana Books, 1986), pp. 9-15, y cfr. S. Guest, Ronald Dworkin (Edinburgh: Edinburgh University Press, 1991), pp. 141-144.

'Cfr. Aulis Aarnio, The Rational as Reasonable (Dordrecht: Kluwer Academic, 1987), pp. $221-225$. 
posible a alcanzar bajo los gobiernos humanos. Entre los valores que puede asegurar ninguno es tan importante como la certeza jurídica, excepto quizás su camarada, la seguridad de expectativas jurídicas y la seguridad de los ciudadanos frente a la injerencia arbitraria de los Estados y de sus agentes ${ }^{3}$.

Si el Estado de Derecho es respetado, la gente puede tener una razonable certeza previa relativa a las reglas y estándares por los cuales su conducta será juzgada y a las exigencias que ellos deberán satisfacer para dar validez juridica a sus transacciones. Pueden entonces tener una razonable seguridad en sus expectativas hacia la conducta de otros, y en particular de aquellos que ocupan posiciones oficiales bajo el Derecho. Pueden cuestionar los actos estatales que afecten a sus intereses, exigiendo una justificación jurídica clara para la acción oficial, o la anulación de los actos no justificados a través de su revisión por una judicatura independiente. Esto es posible, se dice a menudo, siempre y cuando exista un sistema jurídico compuesto principalmente de reglas enunciadas con bastante claridad, que operen normalmente sólo de manera prospectiva, que estén expresadas en términos de categorías generales, no de órdenes particulares que señalen singularmente a individuos o pequeños grupos para una especial consideración. Las reglas deberían establecer exigencias de conducta realmente alcanzables, que formen en conjunto algún modelo coherente, y no un caos de exigencias en conflicto arbitrario ${ }^{4}$.

Mucha gente, y por supuesto yo entre ellos, encuentra atractiva tanto la tesis como la antítesis que acabo de establecer. Creo cn la cualidad argumentativa del Derecho y la encuentro admirable en una sociedad abierta. Deberíamos fijarnos en todos los aspectos de todas las cuestiones importantes, no caigamos inmediatamente en el prejuicio o en la certeza aparente. Debemos oír cada argumento y celebrar, no deplorar, la cualidad argumentable que parece incorporada al Derecho. Pero también creo en el Estado de Derecho, y pienso que nuestra vida como humanos en comunidad con otros se enriquece en gran medida gracias a él. Sin él, no hay expectativas de realizar la dignidad de los seres humanos como participantes independientes, aunque interdependientes, en las actividades públicas y privadas de una sociedad. Este tipo de dignidad y la independencia-en-interdependencia son, a mi modo de ver, valores morales y humanos fundamentales.

¿Cómo es posible creer en ambas tesis? ¿Puede ser esto algo distinto de un mero deseo? Éstas son las cuestiones que se encuentran ante nosotros. ¿Podemos reconciliar el lugar común del carácter argumentable del Derecho con la ideología del Estado de Derecho?

\footnotetext{
"Cfr. J. Raz, "The Rule of Law and its. Virtue», en Raz, The Authority of Law (Oxford: Clarendon Press, 1979), pp. 210-229.

- La cita clásica para este tipo de descripción sigue siendo L. L. Fuller, The Morality of Law (New Haven, Conn.: Yale University Press, ed, revisada, 1969), cap. 2.
} 


\section{HACIA LA RECONCILIACIÓN}

\section{a) Teorias retóricas}

La estrategia que aquí adoptaré para intentar reconciliar los lugares comunes en conflicto se basa en el reconocimiento de una limitación fundamental del proceso de argumentación jurídica. Se trata de la llamada «tesis del caso especial», sugerida por Robert Alexy ${ }^{5}$. Según esta tesis, la argumentación jurídica debe ser reconocida como un caso especial del razonamiento práctico general y debe, por tanto, conformarse a las condiciones de racionalidad y razonabilidad que se aplican a todos los tipos de razonamiento práctico. Esto implica, como mínimo, que no puede haber afirmaciones sin razones; cualquier afirmación puede ser cuestionada, y en tal caso, debe ofrecerse una razón a favor de lo que se afirma, bien se trate de la afirmación de alguna pretensión normativa o bien de algún estado de cosas, de alguna «cuestión de hecho».

Por ello, lo que aquí será analizado y defendido será una versión restringida del carácter argumentable del Derecho. El análisis se limitará a considerar qué es racionalmente argumentable. Decir esto implica distinguir entre el uso de las palabras como meras armas de coerción intelectual o engaño y su uso como instrumento de persuasión razonable, donde la coerción sólo aparece en el sentido de fuerza convincente de un argumento. Es este último, el argumento como justificación racional, el que aquí será analizado. $Y$ la cuestión será si puede haber un «Estado de Derecho», si el «Derecho» es una cuestión de lo que es argumentable en este sentido. Quedará abierta una cuestión empírica acerca de si, o hasta qué punto, los abogados y jueces de un Estado particular realmente limitan su práctica de la argumentación al ámbito de lo razonable prácticamente.

A pesar de la restricción a lo que es racionalmente argumentable, la idea del Derecho como argumentable nos lleva inmediatamente a tomar en cuenta el carácter retórico de la argumentación jurídica. Donde haya un proceso de argumentación pública allí habrá retórica. El moderno redescubrimiento de la retórica como disciplina es en gran medida deudor de la reflexión sobre el razonamiento jurídico. Theodor Viehweg, inspirándose en Aristóteles, ha prestado atención a la relevancia de los topoi o «lugares comunes» en los

"Véase R. Alexy, Theory of Legul Argumentation (Oxford: Clarendon Press, 1989, trad. R. Adler y N. MacCormick), pp. 5-10, 212-220, 294-295, y cfr. N. MacCormick, Legal Reasoning and Legal Theory (Oxford: Clarendon Press, 1978, $2^{\mathrm{a}}$ ed., 1994), tratando sustanciaimente la misma cuestión (pp. 272-274); la Theorie der juristischen Argumentation de Alexy fue publicada por primera vez en 1978, casi exactamente contemporánea a Legal Reasoning and Legal Theory, de modo que cada cual llegó prácticamente a las mismas tesis a partir de procesos de descubrimiento independientes. 
argumentos retóricos ${ }^{6}$. Un argumento a favor de una regla o proposición particular puede apoyarse en algunos tópicos aceptados, y los argumentos progresan a través de su marcha hacia o desde tales posiciones de lugares comunes. En el Derecho existen máximas, principios y presunciones establecidas desde antiguo, tales como «se presume la inocencia de una persona hasta que no se demuestre su culpabilidad», «nadie puede dar un derecho mejor que el que tiene», «la ley posterior deroga a la ley anterior», etc. Del mismo modo, hay formas aceptadas de argumentos, tales como argumentum a fortiori, argumentum a maiori ad minus, argumentum per analogiam, etc. Un argumento así reconocido, que parte de o va hacia un fopos reconocido, está especialmente diseñado para ser persuasivo en su propio contexto. La presente discusión parte ella misma de dos ideas que me parecen lugares comunes aceptados entre aquellos que reflexionamos, aunque sea esporádicamente, sobre el Derecho.

Usando un concepto no muy lejano del «lugar común», Duncan Kennedy sugiere que los argumentos de Common Law típicamente proceden de la alegación de razones estándares, de un tipo que frecuentemente puede encontrarse en parejas, de modo que un argumento jurídico persuasivo será un agregado de razones relativas a la situación de hecho en cuestión, pero puede construirse un contraargumento usando un conjunto de contraargumentos similarmente contextualizado en forma de equipos de razones?. James Palmer ha mostrado que esta idea puede explotarse aprovechando la tecnología de la información e inteligencia artificial como ayuda al proceso de razonamiento jurídico. Puede preverse que los sistemas expertos generarán una batería de razones relevantes para su alegación en relación con los problemas de determinados ámbitos del Derecho. Hasta ahora al menos no se ha sugerido que la evaluación de los argumentos en conflicto así construidos podría o debería ser delegada a los ordenadores; más bien lo que se desea es asegurar que los jueces y abogados se encarguen de construir sus argumentos finales para defenderlos ante un tribunal o desplegarlos en justificación de una decisión a partir de un minucioso listado de argumentos disponibles, basados en la práctica anterior (precedente) y donde resulte apropiado en el Derecho legislado ${ }^{8}$. El presente argumento, tal y como ha sido planteado, presenta dos razones o topoi y los mantiene

${ }^{6}$ Véase T. Viehweg, Topik und Jurispnudenz (Munich: C. H. Beck, 5. ${ }^{a}$ ed., 1974), pp. 15-26; también «Some Considerations concerning Legal Reasoning», en G. Hughes (ed.) Law, Reason and Justice: Essays in Legal Philosophy (New York, 1969), pp. 257-269, esp. 266-268; aquí atopois es traducido por "puntos de vista»; véase también Alexy, Argumentation, pp. 21-24.

? Véase D. Kennedy, A Critique of Adjudication (Cambridge, Mass.: Harvard University Press, 1997), pp. 137-156, y nótense otros autores y trabajos «CLS» citados en la p. 393. Como Kennedy reconoce, la idea fundamental se remonta aquí al menos a los primeros trabajos de Karl Llewellyn —véase, p. ej., Llewellyn, Jurisprudence: Realism in Theory and Practice (Chicago: Chicago University Press, 1962), pp. 70-71.

${ }^{8}$ Véase J. Palmer, Artificial Intelligence and Legal Merì Arguments (Oxford: Oxford University D. Phil. Thesis, 1970), pp. 109-128. 
en mutua oposición. La cuestión es hasta dónde podemos llegar a partir de esta aparente contradicción.

Ciertamente se deberían tener en mente las enseñanzas de Josef Esser acerca de las Voverständnisse, las "precomprensiones", las presunciones asumidas por cualquier juicio acerca de lo que es aceptable en el marco de la argumentación jurídica y en la preferencia, en un caso particular, de un método de argumentación sobre otro. Una vez que las premisas y el modo de argumentar están establecidos, es relativamente fácil elaborar un argumento que justifique satisfactoriamente la conclusión obtenida. Pero el problema entonces se traslada a la elección razonable de las premisas y del método; por ello, deben examinarse las precomprensiones . Aulis Aarnio ha sugerido que al final éstas pueden simplemente tener que ser evaluadas como la «forma de vida» que ellas constituyen $^{10}$.

La Nouvelle Rhétorique de Chaim Perelman enfatiza que los argumentos se dirigen necesariamente a un auditorio y que la persuasividad es relativa al auditorio. Esto es especialmente obvio en la práctica jurídica, donde abogados experimentados exponen los casos ante los tribunales tan persuasivamente como pucden, y los jueces deciden después de sopesar los argumentos rivales sobre las cuestiones de Derecho. En los sistemas donde los jurados son los responsables de la determinación de los hechos o de las conclusiones jurídicas obtenidas a través de sus propias búsquedas de los hechos a la luz del Derecho, tal y como les explica el juez que les preside, el carácter retórico de la argumentación forense es todavía más destacado. Pero desde el punto de vista de la racionalidad práctica, la persuasividad inmediata y concreta de un argumento no equivale necesariamente a su corrección. Para una teoría del razonamiento como justificación lo importante no es que un argumento persuada de hecho a un juez o jurado particular, sino que debería convencer a cualquier agente racional. En este sentido Perelman postula un «auditorio universal», que es el que proporciona el test último: será correcto cualquier argumento que convenciera al auditorio de todas las personas inteligentes y responsables que evalúen las cuestiones de mancra desinteresada ".

Prácticamente contemporáneo al trabajo de Perelman sobre la retórica fue el de Toulmin sobre The Uses of Argument, en el que ofrece un modo de reducir el aparente vacío entre la pura racionalidad supuestamente intemporal de la lógica formal y el carácter contextual de la argumentación y persuasión retóricas. Toulmin propone una reinterpretación de la lógica tradicional como un tipo de ordenación normativa del proceso de pensamicnto y de la presentación pública de las razones, un proceso que regula las ajugadas» de

'J. Esser, Vonverständnis und Methodenwahl in der Rechtsfindung (Frankfurt/Main: Suhrkamp, 1970), pp. 3-20.

19 A. Aarnio, Rational as Reasonable, pp. 213-218.

"Ch. Perelman y L. Olbrechts-Tyteca, La Nouvelle Rhétorique (Paris: Presses Universitaires de France, 1958), trad. J. Wilkinson y P. Weaver, The New Rhetoric (Notre Dame, Ind.: Notre Dame University Press, 1969), véase pp. 76-86 sobre el xauditorio universal». 
los argumentos. Como un ticket que nos permite emprender un cierto viaje en tren o en avión, las formas apropiadas de un argumento suministran las garantías que nos permiten pasar desde las premisas a la conclusión. La validez del paso dependerá de la adecuación de la garantía alegada a su contexto ${ }^{12}$.

El giro retórico en el análisis del razonamiento práctico es inservible para el propósito actual si (o hasta dónde) la aceptabilidad racional de un argumento se reduce a su persuasividad de hecho. Una de las cosas que hace que la retórica tenga mala fama es la notoria posibilidad de que un buen orador pueda ganarse al auditorio con un mal caso. Dar cuenta de esto aludiendo al auditorio universal o a algún supuesto consenso de los contemporáneos razonables parece una petición de principio, ya que, de hecho, encontramos lo que persuadiría al auditorio universal por referencia a lo que es correcto y no al contrario, y no tenemos garantía de que un consenso contemporáneo, si existiera, sería correcto. Aún más, las aproximaciones «críticas» al pensamiento jurídico instan a que la pretensión de corrección objetiva de las razones jurídicas es el mayor giro retórico posible.

Este punto de los «críticos» ya ha sido en parte señalado. A menudo puede construirse un conjunto de razones o «elementos de razonamiento» persuasivos que ofrezcan un firme soporte a la solución de un problema o controversia jurídica. Pero en cualquier situación controvertida, real o imaginaria, puede encontrarse un equipo de contra-razones o contra-elementos para cada una de ellas. Por ello, el problema no es defender correctamente un caso discutible a expensas de un caso manifiestamente más débil. Más bien se trata muy a menudo de una cuestión de elección entre dos casos fuertemente discutibles y defendibles, en una situación dialéctica en la cual cada argumento de cada una de las partes es firmemente rebatido por un buen argumento propuesto por la otra. De este modo, quizás sólo se pueda llegar a una decisión absolutamente justificada, haciendo referencia a consideraciones ideológicas extrañas al Derecho, y la razón justificatoria última será entonces la ideología y no el Derecho ${ }^{13}$. La breve discusión de Hans Kelsen sobre la interpretación en La teoria pura del Derecho señalaría en esta misma dirección ${ }^{14}$.

${ }^{12}$ S. E. Toulmin, The Uses of Argument (Cambridge: Cambridge University Press, 1958), pp. $95-145$

1 Véase J. Balkin, "The Crystalline Structure of Legal Thought", Rutgers Law Rev, 39 (1986), 195; "Nested Oppositions», Yale Law Joumal, 99 (1990), 1669; «Ideological Drift and the Struggle over Meaning», Conn. Law Rev., 25 (1993), 369; cfr. Kennedy, Adjudication, pp. 133-138, y véase Peter Goodrich, Reading the Law: a Critical Introduction to Legal Method and Techniques (Oxford: Blackwell, 1986),pp. 213-223.

" Véase H. Kelsen, The Pure Theory of Law (Berkeley y Los Ángeles: University of California Press, 1967, trad. M. Knight), pp. 251-254, sobre el carácter "político" de las decisiones interpretativas adoptadas en el marco del Derecho legislado. 


\section{b) Teorias procedimentales}

Una aproximación procedimental al razonamiento práctico puede, sin embargo, suministrar una solución parcial a los problemas expuestos relacionados con la retórica. Existen distintas aproximaciones «procedimentales», pero todas ellas comparten el interés en la comprensión de las limitaciones del razonamiento práctico, que deben reconocerse para llegar a conclusiones razonablemente aceptables en un contexto interpersonal. Por ello, un punto de partida es precisamente el énfasis de los retóricos en el contexto interpersonal de la argumentación. Desde esta perspectiva, el concepto de universalidad tiene dos usos. En primer lugar, exige la universalización de las razones: para que el ejemplo presente de circunstancias $\mathrm{C}$ cuente como una razón para obtener la decisión D y actuar según $D$, tendría que ser aceptable adoptar una decisión de tipo D para cualquier ejemplo de C que se diera. En segundo lugar, sugiere un modo de comprobar si se justifica la afirmación de que $\mathrm{D}$ es adecuada cuando se da C. Esta razón universalizada será aplicable, por definición, a todos los ejemplos de C, no sólo al ejemplo individual del que nos ocupamos. Los intereses, sentimientos y opiniones de todos los seres humanos están entonces potencialmente en juego, y se podría preguntar si la fórmula «Si C, entonces D» podría ser rechazada por alguien que deseara que todos tuvieran la misma oportunidad de cuestionar los principios prácticos de decisión ${ }^{15}$.

Tal y como argumentan Jürgen Habermas y sus seguidores, como Robert Alexy, las proposiciones prácticas pueden comprobarse mediante referencia, al menos en principio, a los intereses, sentimientos y opiniones de la totalidad de personas que, de algún modo, se ven afectadas por o se relacionan con ellas. La maniobra de Habermas consiste en proponer un test por referencia al diálogo en una «situación ideal de habla», concebida como aquella en la cual todas las formas de coerción, poder o dominación interpersonal son rechazadas para conseguir los propósitos de guiar (o imaginar la guía de) el discurso interpersonal. El análisis de las limitaciones necesarias en tal discurso provoca una aproximación procedimental para comprobar los tipos de principios que los participantes en el discurso racional aceptarian, reconociendo los tipos de deseos e intereses que de hecho tienen ${ }^{16}$. Lo importante aquí es la idea de que los principios o lugares comunes (topoi) aceptados deberían ser «desafiables», pero son considerados aceptables hasta que sean exitosamente rebatidos; por ejemplo, sobre la base de que no pueden pasar el test de universalización, o sobre la base de que proceden de relaciones sociales de poder pasadas o presentes, que serían rechazadas en la situación ideal de habla ${ }^{17}$.

is Cfr. Alexy, Argumentation, pp. 65-69, 146-147, 267-277; MacCormick, Legal Reasoning, pp. $76-86$.

${ }^{15}$ Habermas, The Legitimation Crisis (London, 1976, trad. A. McCarthy), pp. 109-112; cfr. Alexy, Argumentation, pp. 111-137.

"Véase Alcxy, Afgumentation, pp. 151-153, 204-205. 
Una idea similar, pero más simple y por tanto más persuasiva, es la de T. M. Scanlon ${ }^{18}$, quien sugiere que una acción es incorrecta cuando cualquier principio que la permitiera pudiera ser, por esa razón, rechazado por alguien, incluso si se llevara a tal persona a encontrar principios para la regulación general de la conducta que otros, similarmente motivados, tampoco pudieran rechazar razonablemente ${ }^{19}$.

Es dudoso si tal aproximación procedimental elimina completamente el rccurso a los sentimientos personales o a las intuiciones subjetivas. Hay que indagar, pues, las razones que nos conducirían a rechazar un cierto principio por nosotros mismos, y la cuestión tiene aún que enfrentarse a lo que para cualquiera es «razonable» rechazar, dados los sentimientos y precomprensiones con los que se va al juicio. El procedimiento de examinar procedimentalmente los argumentos no puede ser infinitamente regresivo. Pero seguramente es un mérito de tales aproximaciones procedimentales el posponer y limitar las llamadas a la intuición ${ }^{20} \mathrm{y}$ al instinto. Nos permitirían examinar las pretensiones acerca de lo que es razonable a la luz de las limitaciones reconocidas del discurso racional. Los principios de lugares comunes siguen siendo necesarios como puntos de partida, pero resultan rebatibles en la argumentación.

La racionalidad de la argumentación introduce otra limitación relevante. Aunque cualquier dilema práctico particular o tópico de interés pase a ser considerado en sus propios méritos y se someta a procedimientos como los que hemos considerado, debe recordarse que los universales (Si C, entonces D) de los que nos ocupamos no pueden ser concebidos como exigencias aisladas y puntuales. Somos nosotros los que decidimos considerarlos como parte de una vida social dinámica e interpersonalmente comprometida en la cual las decisiones y los dilemas tienen carácter recurrente. Esto se encuentra fuertemente relacionado con lo que razonablemente puede ser aceptado o rechazado en términos del meta-principio de Scanlon o de la situación ideal de habla de Habermas. Por eso, los propios principios y reglas de decisión y de conducta tienen que pertenecer a un sistema de pensamiento y compromiso práctico internamente consistente y caracterizado también por cierta coherencia glo-

"Véase T. M. Scanlon, "Contractualism and Utilitarianism», en A. Sen y B. Williams (eds.), Utititarianism and Beyond (Cambridge: Cambridge University Press, 1982), pp. 103-128, y What We Owe to Each Other (Cambridge, Mass.: Harvard University Press, 1998). Dado que ningún acuerdo o contrato real está implícito en tal razonamiento, y que las obligaciones generadas por o bajo él no son de hecho de carácter contractual, me parece rechazable llamar a este tipo de análisis procedimental de los principios prácticos como acontractualista»; pero su valor como razonamiento no se ve afectado por el nombre que recibe. Cfr. MacCormick, «Justice as Imparciality: Assenting with Anti-contractualist Reservations», Political Studies, 44 (1996), pp. 305-310.

"Citado por T. M. Scanlon, "Promises and Contracts», versiốn preliminar de un trabajo para Philosophy and Contruct Law (en prensa, ed. P. Benson, Cambridge, Cambridge University Press).

${ }^{20}$ M. J. Detmold, The Unity of Law and Monality (London: Routledge, 1984), en las pp. 115-122 subraya correctamente cl elemento de intuición en el juicio, pero deja demasiado abierto el marco para su ejercicio. 
bal ${ }^{21}$. Esto implica, como mínimo, algunas pautas sobre la ordenación de la prioridad y procedimientos para determinar los pesos relativos de las razones prácticas para resolver conflictos prima facie.

Es útil recordar aquí el punto de partida del presente hilo de razonamiento, expresable en un puzzle sobre la aparente antinomia entre el Derecho como aquello que es argumentable y el Derecho como aquello que garantiza la seguridad y estabilidad en la vida social de un Rechisstaat. Hasta ahora hemos considerado de manera un tanto abstracta la idea de un compromiso retórico en la práctica del Derecho y hasta qué punto un desarrollo procedimental o discurso-teorético de las ideas de la «nueva retórica» brindan la posibilidad de un esquema racional aceptable para la argumentación en el Derecho y en otros ámbitos prácticos.

En el contexto jurídico, sin embargo, la idea de coherencia recién mencionada tiene una particular y obvia relevancia ${ }^{22}$. En un razonamiento jurídico nadie empieza desde cero y elige desarrollar una conclusión razonable a priori. La solución ofrecida debe basarse en alguna proposición que pueda al menos presentarse con el cariz de una proposición jurídica, y tal proposición debe mostrarse coherente de alguna manera con el Derecho, tal y como éste esté determinado. Los argumentadores y decisores jurídicos no abordan los problemas de decisión y justificación en el vacio, sino en el contexto de una gran cantidad de material que sirve para guiar y justificar decisiones y para restringir el abanico en el cual las decisiones de los órganos públicos pueden ser legítimamente tomadas.

El material en cuestión comprende las constituciones, los tratados, las leyes de los parlamentos nacionales y las numerosísimas compilaciones de las decisiones de los tribunales de justicia reconocidas en algunos sistemas como "precedentes», en el sentido de «fuente formal de Derecho», y usados en prácticamente todos los sistemas jurídicos ${ }^{23}$ al menos como un repertorio de guías disponibles para la interpretación de leyes, artículos constitucionales y otras disposiciones jurídicas formalmente vinculantes. Se incluyen también los tratados y otros trabajos académicos sobre el Derecho de reconocidos expertos jurídicos.

"Véase A. Peczenik, On Law and Reason (Dordrecht/Boston/London: Kluwer Academic Publishing, 1989).

"Véase Kennedy, Adjudication, pp. 33-34; N. MacCormick, "Coherence in Legal Reasoning", en W. Krawietz y otros (ed.), Theorie der Nomen (Berlin: Duncker \& Humblot, 1984), pp. 37-53, y «Time, Narratives, and Law», Archiv für Rechts- und Sozialphilosophie, Beiheft 64, Time, Law, and Society, J. Bjarup y M. Blegvad (eds.), pp. 111-125.

" Véase D. N. MacCormick \& R. S. Summers, Interpreting Precedents: A Comparative Siudy (Aldershot: Dartmouth Publishing Co, 1997). 


\section{c) Derechos}

Es usual decir que esta gran cantidad de material no es y no puede imaginarse como autointerpretable y autoaplicable. Desde la perspectiva del «Estado de Derecho» ideal debe entenderse como el material en bruto de un «sistema jurídico", organizado en conjuntos inteligibles de material relevante para asuntos humanos particulares en las ramas o ámbitos tradicionales del Derecho, tales como la propiedad, el contrato, el Derecho de familia, el Derecho penal o el Derecho administrativo ${ }^{24}$. En el contexto de los Estados como asociaciones coercitivas de seres humanos, a los Estados y a aquellos seres humanos que desempeñan roles estatales se les confiere el poder para actuar autoritativamente frente a otros, y pueden respaldar sus disposiciones con decisiones que desplieguen el poder coactivo organizado. En este punto urge la exigencia de la justificabilidad racional de la acción del Estado para evitar que el Estado sea una mera máscara de la tiranía. De ahí que haya llegado a ser generalmente entendido como legítimo exigir que cualquier acto estatal se justifique en disposiciones explícitas que ordenen, permitan o autoricen decisiones en términos específicos (o que incluyan alguna discreción limitada sólo si se dan ciertas circunstancias nítidamente especificadas). Las disposiciones de este tipo, especialmente cuando son promulgadas específicamente por algún proceso legislativo, pero también cuando pueden derivarse en términos razonablemente definidos a partir de otros materiales, tales como los precedentes, son típicamente llamadas «reglas», en contraposición a otros tipos de normas, tales como las convenciones, los estándares, los valores o los principios ${ }^{25}$.

Una regla jurídica es una disposición normativa establecida en, o construida a partir de, una fuente juridica reconocida que vincula una determinada consecuencia normativa a unos determinados hechos operativos. Está en la naturaleza de una regla prever que cuando se dé una cierta situación de hecho se siga de ello una determinada consecuencia normativa: «Si HO, entonces $\mathrm{CN}$.

En el núcleo de la idea liberal del Estado libre y en el núcleo de la distinción entre gobiernos libres y despóticos se encuentra la idea de que cuando los gobiernos actúan frente a los ciudadanos su acción debe ser justificable mediante una regla en este sentido del término, y esto también vale cuando el Estado, generalmente a través de los órganos judiciales, pretende regular o juzgar las pretensiones, reclamaciones y demandas interpuestas entre ciudadanos. El Estado de Derecho también exige aquí que haya alguna regla que justifique la demanda de una persona contra otra cuando la aplicación de la demanda

24 Véase J. Wroblewski, The Judicial Application of Law (Dordrecht/Boston/London: Kluwer Academic, 1992, cd. Z. Bankowski y N. MacCormick), pp. 75-85.

${ }^{25}$ Para una aclaración de estas distinciones véase N. MacCormick, «Norms, Institutions, and Institutional Facts», Law and Philosophy, 17 (1998). 
genere una orden ejecutable contra el otro, por ejemplo, un resarcimiento por daños compensatorios o punitivos, o un interdicto.

Los códigos y las leyes de la época moderna, asî como otros materiales, representan una respuesta institucional a la ideología ${ }^{26}$ del «Estado de Derecho" como condición para la libertad. El Estado que gobierna a través del Derecho tiene cuidado en prever de antemano los textos de las reglas que justifican las intervenciones públicas en las vidas privadas, bien sean instadas por autoridades públicas o por litigantes privados. La seguridad para los individuos así garantizada consiste en el hecho de que la aplicación de las reglas cxige cvidentemente la previa existencia de hechos especificos que ejemplifiquen los hechos operativos «HO» genéricamente establecidos en las reglas relevantes. Así, por ejemplo, si una ley tutela a las personas que sufran discriminación "por razón de sexo", no podrá justificarse ninguna medida para implementar las consecuencias normativas previstas por la regla, a no ser que en un caso particular haya ocurrido algún acto de discriminación, haya tenido lugar en el contexto de una relación laboral y sea atribuible al sexo de la persona a la que se discrimina ${ }^{27}$. $O$ si una regla prevé la retirada del permiso de conducir, u otra sanción determinada discrecionalmente por el juez de entre un abanico de posibilidades, para quien conduzca un vehículo de motor bajo la influencia de más de una determinada proporción de alcohol en sangre, no podrá imponerse legítimamente ninguna sanción a nadie salvo que se justifique por su estado en la condición especificada y por haber "conducido" un avehículo" en tal condición ${ }^{28}$.

Si el Estado de Derecho debe ser realmente una protección contra la intervención arbitraria en la vida de la gente, parece claro que, en la práctica, no basta con exigir que los hechos operativos efectivamente ocurrieron o tuvieron lugar en alguna ocasión. Es necesario que se realice alguna específica y rebatible acusaciốn o declaración de hechos relevantes sobre el individuo amenazado con la acción, y que dicha acusación o declaración se base en un procedimiento probatorio abierto, en el cual la parte acusada pueda refutar paso por paso las distintas pruebas en su efecto acumulativo y pueda ofrecer las contrapruebas que considere relcvantes. Por otra parte, también debe ser posible cuestionar la relevancia de la acusación o demanda jurídica sobre la basc de que cualesquicra que sean los hechos los materiales jurídicos que

${ }^{2 \sigma}$ Por supuesto, en este contexto el término kideología no es usado en su sentido peyorativo. Cfr. Wróblewski, Judicial Application.

${ }^{27}$ Véase Oncale us. Sundowner Offshore Senices Inc, US Supreme Court N." 96-568 (March 1998), donde la Supreme Court sostiene que el acoso al mismo sexo podría equivaler a una infracción de las previsiones antidiscriminatorias del Titulo VII de la Civil Rights Act de 1964.

2 Véase State ws. Blower, Utah, 1989, sobre si puede decirse que una persona que monta un caballo estando bebida está a cargo de un «vehículon; J. Palmer, Merit Arguments, pp. 36-38, cita una fascinante cantidad de precedentes de varias jurisdicciones que ilustran la indeterminación del predicado «conducir» en el contexto de las determinaciones judiciales sobre el delito que cometen aquellos que sconducens un vehículo de motor estando descalificados para hacerio. 
supuestamente justifican la afirmación de que una regla rige el caso en absoluto la justifican en la situación de hecho alegada o realmente probada.

Nos encontramos aquí en el terreno familiar de la relativa indeterminación del Derecho ${ }^{29}$. Esta indeterminación es, de manera curiosa, magnificada por algunas consideraciones que conducen a la exigencia de un Derecho determinado. El carácter dialéctico o argumentativo de los procedimientos jurídicos es, pues, un rasgo incorporado a un marco constitucional en el cual los ciudadanos pueden cuestionar las alegaciones de hechos y de Derecho sobre las que se basan los órganos estatales para amenazar con intervenir, de oficio o a instancia de parte, coercitivamente en sus vidas o asuntos. Una parte vital de la garantía de la libertad en la concepción dominante del Estado de Derecho consiste en que debe darse a todas las personas la oportunidad de exponer tal refutación en términos claros y con la asistencia jurídica adecuada. E incluso la misma concepción dominante exige un Derecho relativamente claro y determinado en forma de reglas preanunciadas.

La indeterminación jurídica no es entonces sólo (aunque tambićn lo sea) resultado del hecho de que los Estados comuniquen sus materiales jurídicos en lenguajes naturales («oficiales») y de que éstos se vean afectados por la ambigüedad, vaguedad y textura abierta ${ }^{30}$. También resulta de, y es en alguna medida magnificado por, el debido reconocimiento a los ederechos de defensa» en cada fase del proceso penal o del litigio civil. Cada duda que pueda surgir contra la acusación o contra el demandante, referida a los hechos o al Derecho, puede ser utilizada por la defensa. Por otro lado, cuando parezca haber en juego una cuestión relevante de justicia o de orden público la acusación o el demandante tendrán razones para buscar en los materiales jurídicos alguna disposición que, bajo alguna interpretación razonablemente defendible, justifique la acción civil o la acusación penal entablada en el presente caso. $\mathrm{Y}$ entonces la defensa rebatirá de nuevo lo que caracteriza como una lectura forzada o ilegítima del Derecho, teniendo en cuenta cómo los tribunales, abogados y ciudadanos la habían previamente entendido y actuado conforme a ello.

De este modo surgen conflictos sobre la interpretación adecuada de los materiales jurídicos, sobre la extracción adecuada de inferencias a partir de las pruebas, sobre la evaluación de las pruebas en conflicto, sobre la calificación adecuada de los hechos probados o acordados o sobre su relevancia para los materiales jurídicos alegados ${ }^{31}$. Estos conflictos no son ningún tipo de excrecencia patológica en un sistema que, de otro modo, funcionaria tranquilamente.

29 Véase S. J. Burton, An Introduction to Law and Legal Reasoning (Boston/Toronto: Little Brown \& Co, 2. ${ }^{2}$ ed., 1995), pp. 27-28, 54-58,77-85.

${ }^{30}$ Cfr. H. L. A. Hart, The Concept of Law (Oxford: Clarendon Press, 2. a ed., 1994), cap. 7, y cfr. B. Bix, Law, Language and Legal Determinacy (Oxford: Clarendon Press, 1993), pp. 7-35; MacCormick, «On Open Texture in Law», en P. Amselek y N. MacCormick (eds.), Controversies about Law's Ontology (Edinburgh: Edinburgh University Press, 1991), pp. 72-84.

"Cfr. MacCormick, Legal Reasoning, pp. 65-72. 
Son un elemento integral de un orden jurídico que trabaja según el ideal del Estado de Derecho, hasta el punto de insistir en la elaboración por los Estados de una apropiada justificación jurídica para todo lo que hagan, paralela al derecho de los individuos a rebatir la justificación elaborada por el Estado.

Esto nos conduce a una conclusión obvia. Aunque sea posible formular reglas con una fórmula verbalmente clara, «Si $\mathrm{HO}$, entonces $\mathrm{CN}$, cualquier caso discutible puede ser rebatido de alguna o algunas de las siguientes maneras:

1. Ningún supuesto de «HO» de los alegados por la acusación o la demanda ha sido probado (según el estándar probatorio exigido), tomando en cuenta todas las pruebas relevantes y admisibles, incluyendo cualquier refutación de alguna prueba alegada por la defensa (podemos llamar a esto kproblema de prueba»).

2. Lo que ha sido alegado, sea o no probado, no es propiamente caracterizado como un caso de «HO» en el sentido propio para el Derecho (podemos llamarle "problema de caracterización" o de "clasificación» o de "calificación»).

3. El caso tal y como ha sido presentado depende de una lectura de la regla aceptada «Si $\mathrm{HO}$, entonces $\mathrm{CN}$, acorde a una determinada interpretación de $\ll \mathrm{HO} » 0$ de $« \mathrm{CN} » 0$ de ambas. Pero se trata de una mala interpretación, y existe de hecho una interpretación jurídicamcnte más accptable, según la cual la defensa debería ser absuelta de la acusación o demanda que se dirige contra ella (podemos llamarle «problema de interpretación»).

4. El éxito de la demanda o acusación depende de si se considera que los materiales jurídicos autoritativos generan una regla, $\alpha \mathrm{Si} \mathrm{HO}$, entonces $\mathrm{CN} »$, tal que las alegaciones de culpa penal o de responsabilidad civil resulten relevantes dados los hechos alegados, 0 incluso probados, pero tal norma no puede ser adecuadamente entendida de ese modo a partir de los materiales aducidos, bien como una concreción razonable de los mismos o como una determinación a partir de ellos. (Podemos llamarle «problema de relevancia».)

Podemos ahora pasar a la conclusión. Hemos visto cómo los procesos jurídicos se despliegan a lo largo de una cadena de certezas putativas que resultan rebatibles en cada punto. No puede llevarse a cabo ninguna demanda o acusación sin una mención adecuada de la justificación jurídica que la respalda y sin dar cuenta de las alegaciones de hechos on virtud de las cuales se afirma que el Derecho justifica la conclusión propuesta (por la acusación o por el demandante). Ésta posee la completa certeza lógica que resulta inherente a la forma silogistica ${ }^{32}$. Hay una regla «Si $\mathrm{HO}$, entonces $\mathrm{CN} »$, citada por la acusación o el demandante en sus escritos, donde también se alega que los

${ }^{32}$ Para una visión opuesta cfr. B. S. Jackson, Law, Fact and Narrative Coherence (Liverpool: Deborah Charles, 1988), pp. 37-60; en respuesta a la cual yéase N. MacCormick, «Notes on Narrativity and the Normative Syllogism, Intemational Joumal for the Semiolics of Law, IV/11 (1991), pp. 163-174; «Legal Deduction, Legal Predicates, and Expert Systems», Intemational Joumal for the Semiotics of Law, V/14 (1992), pp. 181-202, y «A Deductivist Rejoinder to a Semiotique Critiquem, International Joumal for the Semiotics of Law, V/14 (1992), pp. 215-224. 
HO han ocurrido en un caso concreto en el tiempo especificado, de modo que involucran materialmente al acusado o demandado. Por eso la consecuencia normativa relevante $\mathrm{CN}$ debería ser ejecutada tal y como se exige. Éste es el silogismo jurídico estándar ${ }^{33}$, incluido de varias maneras en la acusación penal o demanda civil y en la sentencia.

Pero la conclusión es sólo buena en la medida en que lo sean las premisas, y éstas pueden ser problematizadas. Se puede rebatir la prueba, la calificación, la interpretación o la relevancia (una, algunas o todas ellas). Pero la idea del Estado de Derecho que aquí ha sido sugerida insiste en el derecho de la defensa a cuestionar y refutar la argumentación presentada contra ella. No hay seguridad contra un Estado arbitrario sin que tales cuestionamientos sean libremente permitidos y sujetos a aplicación por órganos del Estado separados y distintos de aquellos órganos que acusan. En la litigación de Derecho privado aparece una exigencia similar en ta necesidad de una visible imparcialidad del juez.

Después de escuchar las pruebas y las argumentaciones el tribunal debe decidir. Al decidir las cuestiones surgidas en los problemas de calificación, de interpretación o de relevancia el tribunal puede considerar necesario y adecuado desarrollar una nueva comprensión del Derecho, establecer un nuevo precedente, que puede confirmar o modificar comprensiones previas. Al final, o bien el caso es rechazado por inconcluyente, siendo absuelto el demandado, o bien el tribunal adopta algún fallo que se justifique a la luz del Derecho, tal y como ha sido precisado en la resolución de los problemas expuestos. $\mathrm{Y}$ entonces hay, en efecto, un silogismo concluyente. Pero es en todo caso raramente idéntico al silogismo inicial. Es una nueva certeza derrotable que ha surgido de la exposición de los problemas sobre la vieja certeza derrotable y de su resolución por argumentos racionales ${ }^{34}$. Desde la confrontación del carácter argumentable del Derecho llegamos hasta la reafirmación de una nueva certcza putativa después de admitir y de ocuparnos de las dudas sobre lo antiguo.

Al fin y al cabo, debe reconocerse que la originaria representación del Estado de Derecho como antítesis del carácter argumentable del Derecho se equivocaba en el énfasis que ponía en la certeza del Derecho. Por más cuidado que los legisladores, los drafters, o los jueces que plasman sus opiniones inten-

${ }^{37}$ Cfr. Kennedy, Adjualication, pp. 101-104; Burton, Introduction, pp. 43-58.

${ }^{34}$ Sobre la derrotabilidad véase H. L. A. Hart, *The adscription of Responsibility and Rightsw, Proceedings of the Aristotelian Society, 49 (1948-1949), pp. 171-194, del cual se retracta Hart en Punishment and Responsibility (Oxford: Clarendon Press, 1968), Prefacio; vease también G. P. Baker, «Defeasibility and Meaning», en Law, Morality and Society, ed. P. M. S. Hacker y J. Raz (Oxford: Clarendon Press, 1977), pp. 26-57. Cfr. N. MacCormick, sLaw as Institutional Factw, Edinburgh University Inangural Lecture No 52, 1983; Law Quarterly Review, 90 (1974), pp. 102-129; ahora en N. MacCormick y $\mathrm{O}$. Weinberger, An Institutional Theory of Law, Dordrecht, D. Reidel Publishing Co, 1986, cap. 2, ahora sustituido por MacCormick, «Defeasibility in Law and Logical", en Z. Bankowski e I. White, Informatics and the Foundations of Legal Reasoning (Dordrecht: Kluwer Academic, 1995), pp. 99-117. 
tando establecer una ratio con carácter ejemplificante pongan en los materiales de las fuentes del Derecho, las afirmaciones de Derecho que éstos establezcan como justificaciones para la acción estatal, dirigida a justificar un derecho público o privado, serân siempre derrotables y a veces derrotadas al ser rebatidas por la defensa. La certeza del Derecho es, por tanto, certeza derrotable. Pero esto no es, después de todo, algo que contraste con el carácter argumentable del Derecho, sino algo que aclara una razón subyacente a dicho carácter. Se trata de una concepción de los derechos de la defensa construida en la ideología del Estado de Derecho, en su calidad de protector contra la acción arbitraria de los Estados.

Para concluir podemos entonces confiar en que la retórica del presente trabajo, partiendo de una aparente oposición de ideas, expresadas en dos lugares comunes o razones en conflicto, triunfe en su intento de reconciliarlos, desenmarañando su situación real en el contexto jurídico. Si el Estado de Derecho se toma como ideal aislado, existe el riesgo de no comprenderlo adecuadamente. En ese caso quizás se acentúen sus aspectos más estáticos, centrados en la certeza y seguridad jurídicas de las expectativas juridicas. Pero también tiene un aspecto dinámico, centrado en los derechos de la defensa y en la importancia de permitir que todo lo que sea argumentable sea argumentado siempre que la defensa -o la acusación- desee examinar un argumento jurídico razonable. En este aspecto dinámico cl carácter argumentable del Derecho no es la antítesis del Estado de Derecho, sino uno de sus componentes. 